\title{
Lima en las Tradiciones peruanas de Ricardo Palma
}

\author{
Marco Martos Carrera \\ Academia Peruana de la Lengua \\ marcomartos9@hotmail.com \\ Lima-Perú
}

\section{Resumen}

Las Tradiciones peruanas de Ricardo Palma, leídas y disfrutadas por numerosas generaciones, han sido estudiadas por los críticos desde distintas perspectivas y en el sentir de la mayor parte de personas que las conocen expresan de un modo peculiar el acontecer de la vida en el Perú durante los siglos XVI, XVII, XVIII y XIX a través de los más variados personajes de diferentes estratos sociales. De manera lateral se ha advertido la importancia de Lima en el centro de esta obra narrativa. El texto se propone precisar el lugar preponderante de la Ciudad de los Reyes en la más importante obra narrativa de nuestro escritor. Y analizar algunas formas de composición en este múltiple libro.

Palabras clave: Ricardo Palma, Tradiciones peruanas, Lima.

\section{Abstract}

The Peruvian Traditions of Ricardo Palma, read and enjoyed by many generations, have been studied by critics from different perspectives, and from most people who know them they express in a peculiar way the events of life in Peru during the 16th, 17th, 18th and 19th centuries through the most varied characters from different social strata. The importance of Lima has been noticed in the center of this narrative work. The text intends to specify the preponderant place of the City of Kings in the most important narrative work of our writer. And to analyze some forms of composition in this multiple book.

Keywords: Ricardo Palma, Peruvian Traditions, Lima. 


\section{Marco Martos Carrera (Perú)}

Escritor, poeta y periodista peruano. Es considerado uno de los principales representantes de la Generación del 60 en la poesía peruana. Presidente de la Academia Peruana de la Lengua, catedrático de la Universidad Nacional Mayor de San Marcos y exdecano de la Facultad de Letras y Ciencias Humanas de dicha casa de estudios. 


\section{Introito argumentativo}

El intérprete más preciso de lo que Unamuno llamaba la «intrahistoria» del Perú colonial, sin duda, es Ricardo Palma. Por su pluma llena de gracejo desfilan los más variados personajes de diferentes grupos sociales, aristócratas y plebeyos, militares y clérigos, damas acicaladas y mujeres de los mercados, jovenzuelos atrevidos y hombres provectos sedientos de poder, religiosos y réprobos, hombres y mujeres de vida liviana, santos hombres y mujeres que consideran que el tránsito por este mundo, valle de lágrimas, es solamente la estación previa para la vía eterna. Poco se ha reparado, aunque no se ha dejado de advertir que, en esos relatos comprimidos, en los que historia se da la mano con la ficción en un mismo tejido de palabras, el espacio predominante es la ciudad de Lima, llamada Ciudad de los Reyes, desde su fundación hasta los albores de la república. De las 453 tradiciones incorporadas a la edición más popular (Palma, 1956), la gran mayoría se desarrolla en Lima. Vistas en su temporalidad, las tradiciones apenas se ocupan de la época de los incas y del periodo de la conquista española. Palma en solo seis narraciones cubre ese espacio temporal. Más de 200 tradiciones se ocupan de los tres siglos siguientes y 160 tradiciones transcurren entre 1760 y 1830 , a las que pueden sumarse las llamadas tradiciones en salsa verde que son seis. Solo 51 tradiciones ocurren en el periodo de la república. De toda esta gruesa estadística pueden deducirse algunas afirmaciones, una, que la etapa menos conocida de la historia del Perú es para Palma la época anterior a la llegada de los españoles y la misma época de la conquista, lo cual es natural puesto que las fuentes eran más escasas que ahora y la arqueología no estaba desarrollada. Siendo un letrado, acostumbrado a manejarse en bibliotecas públicas y privadas es natural que Palma conociese mejor la época del virreinato cuando se había consolidado el poder español en estas tierras. El tiempo que conoce Palma mejor es el que va desde 1760 hasta su propio nacimiento en 1833 . 
Cuando es un niño, adolescente o joven adulto todavía puede alternar con personas que vivieron en esos años, lo que le permitió entrelazar las versiones orales con los datos que encontraba en los repositorios. De este encuentro entre la oralidad de sus contertulios con lo que decían los libros y pergaminos, nace el grueso de sus tradiciones, aderezando, con una imaginación prodigiosa que tiene la tendencia permanente a resolver con un chascarrillo, con una broma, las situaciones más complejas de las relaciones entre los seres humanos. Palma gustaba llamarse a sí mismo historiador, y seguramente esa afirmación puede discutirse desde el punto de vista contemporáneo, pero no tanto en la época que le tocó vivir, puesto que lo que cuenta casi siempre parece basado en documentación fidedigna, lo cual, como sabemos bien ahora, es bastante dudoso. Palma ofrece una imagen del pasado que intuitivamente parece verdadera a la mayor parte de los peruanos, aunque no lo sea en el sentido más riguroso. Ese primer equívoco ha conducido a identificar a las tradiciones salidas de su pluma con la historia nacional y también, concomitantemente, a confundir historia nacional con virreinato, y a confundir virreinato con lo ocurrido en ese periodo en Lima. Esta cadena de equívocos se ha venido repitiendo por años, tal vez no tanto en las investigaciones y los ensayos, pero sí en la conciencia popular.

Esa Lima no ha sido inventada por Palma, se le ha atribuido. No es cierto que él imagine una ciudad apacible colmada de cortesanos respetuosos y respetables, sin conflictos, tampoco es verdad que él haya creado un estupefaciente literario que impide ver el rostro horrible de Lima como sostiene Sebastián Salazar Bondy (1964). Y dentro de ese mismo pensamiento, aunque dicho con sutil elegancia, tampoco es verdad monda y lironda lo escrito por Julio Ramón Ribeyro (1981, p. 68) quien sostiene que si la imagen de Palma subsiste es porque nadie ha sido capaz de desembarazarnos de ella. 
El perfil de Palma es literario, si lo recordamos es por lo bien que escribía. Tenía el apego literario a la historia, como Walter Scott, pero como individuo de estirpe romántica, está más preocupado de la forma que de los rigurosos contenidos. Para Palma vale aquello que Menéndez Pidal dice de los escritores españoles, que sienten poética la historia. La historia está siempre presente en lo que escribe Palma, como un aire, como un viento, como un perfume profundo y poderoso, pero también como un designio ineluctable. Palma, de acuerdo a ciertos modelos de la época que él encarna, era un liberal y anticlerical y estaba muy lejos de ser un escritor áulico, pues en ningún momento exalta a la colonia como un paraíso perdido. Se deleita más bien en poner motes a los virreyes, en señalar lo ridículo de llevar la ley hasta extremos risibles, como en aquel incidente de dos carrozas de nobles en las calles de Lima, donde ninguno de los conductores cede el paso, en el convencimiento de que cada escudo de estos aristócratas tenía más valor que el otro.

Ahora bien ¿cómo es esa literatura de Palma? No es este el lugar para entrar a discutir o confrontar cada una de las definiciones que se han dado sobre la entraña de las tradiciones. Eso ya se ha hecho muchas veces y de todas ellas cabe rescatar la idea central de que Palma es profundamente original, no tanto por las cosas que cuenta, sino por la manera de narrarlas. Su prosa es cautivante, nadie lo duda, pero hay algo más profundo todavía y es la estructura de cada tradición, el método de trabajo. Examinando muchas de sus tradiciones, tratando de ver cuál es la forma de narrar, llegamos a la conclusión de que es la que utilizan los antropólogos del siglo XX y XXI, la observación participativa, Palma, en eso, también es un adelantado. La antropología, según ahora bien se sabe, es una ciencia integradora que estudia al ser humano en el marco de la sociedad y la cultura, a las que pertenece; al mismo tiempo es un producto justamente de la actividad social. Se ocupa del origen y desarrollo de toda la gama de variabilidad humana y 
los modos de comportamientos sociales a través del tiempo y el espacio; es decir, del proceso biológico y social de la existencia humana. Estudia al ser humano, de forma integral, tanto en forma de su naturaleza, que lo hace semejante a los animales, como de su cultura, que es un rasgo no biológico. Como el campo de la antropología es muy vasto, con el tiempo se han creado ramas dentro de ella, antropología física, arqueología, lingüística, antropología social. Esta última es la más cercana al trabajo de Palma. Si así fuera, como este trabajo, a través de algunos ejemplos, quiere mostrar, Palma sería, para sorpresa de muchos, un antecedente cultural de José María Arguedas, no tanto en las novelas y cuentos del afamado narrador del siglo $\mathrm{XX}$, sino en los trabajos de su especialidad en los que comparó los usos y costumbres de distintos pueblos peruanos y españoles. Yerran, como lo ha dicho Alberto Flores Galindo (1984, p. 184), quienes reprochan a Palma que no ha trazado el perfil de ningún tipo social de la época virreinal. Esa no es tarea de un escritor, aunque sí de un sociólogo. Aparecen en las tradiciones distintos personajes de índole aristocrática, pero no existe, sin duda, la imagen total de la aristocracia. De igual manera, aparece la plebe, pero no el plebeyo como arquetipo. Si lo hubiera hecho, a Palma le hubieran reprochado tal vez lo contrario, que trabajaba personajes marioneta, no verdaderos seres humanos. Además, los destinos particulares de las personas que retrata Palma, en el sentido más estricto, no llegaron a constituirse en una clase social. Y esa es la gracia suprema de Palma, mostrarnos diversos tipos humanos, en una sociedad en ebullición, buscando su destino. Ni el Perú ni Lima tuvieron hasta el siglo XIX una novela representativa, como sí lo tuvo Rusia con Tolstoi o Francia con Balzac, pero sin duda alguna, las Tradiciones peruanas de Palma llenan ese vacío. Las razones de la ausencia de novela en la sociedad peruana, y siendo más estrictos, la ausencia de escritores de fuste tiene que ver con el carácter masivamente oral de la 
sociedad peruana, no solamente en la sociedad que encontraron los españoles, sino en la misma que ellos empezaron a forjar. Los nacidos en el Perú en las primeras décadas posteriores a la llegada de los españoles aprendían el castellano como una lengua de conquista, impuesta, y la usaban para fines prácticos. En términos estadísticos, entre ellos no podía nacer un gran escritor. Por cierto, existe el Inca Garcilaso, una vez más como excepción. Por su escritura, es un hombre del renacimiento, y por su práctica, por sus decisiones, se fue alejando de las fuentes naturales que lo habían amamantado, a tal punto que, según propio testimonio, se fue olvidando algo del quechua que era su idioma materno. Hubieron de pasar varios siglos para que aparecieran en nuestras tierras algunos escritores de fuste como Juan Espinosa Medrano o Pedro Peralta y Barnuevo, que siendo notables no llegaron a tener una acabada creatividad. En el siglo XIX, el primer escritor verdaderamente original fue Mariano Melgar, y el segundo, de potencia extraordinaria, Ricardo Palma.

\section{Lectura y comentario de algunas tradiciones características}

La tradición que se llama «La procesión de ánimas de San Agustín» (Palma, 2001) explica, en sus inicios, uno de los modos escriturales de Palma. Dice:

No hay limeño que, en su infancia, no haya oído hablar de la procesión de ánimas de San Agustín. Recuerdo que antes de que tuviésemos alumbrado de gas, no había hija de Eva que se aventurase a pasar, dada la medianoche, por esa plazuela, sin persignarse previamente, temerosa de un encuentro con las ciudadanas del purgatorio.

Ni Calancha ni su continuador el padre Torres hablan en la Crónica Agustina de esta procesión, y eso que refieren 
todavía más estupendas. Sin embargo, en el «Suelo de Arequipa convertido en cielo» se relata del alcalde ordinario don Juan de Cárdenas algo muy parecido a lo que voy a contar.

A falta pues, de fuente más auténtica, ahí va la tradición tal como me la contó una vieja muy entendida en historias de duendes y de almas en pena (p. 217).

En este texto, de alguna manera, emblemático, en pocas líneas, Palma hace el resumen de sus maneras de contar. La primera de las fuentes aludidas, es lo que cree la gente, lo que está en el aire de época. Y en este caso, Palma habla desde su propia experiencia, es decir, desde lo que en la antropología contemporánea se conoce como observación participativa. Y alude también al pasado inmediato, que de alguna manera comparte con sus lectores primeros, alude al temor de las mujeres a aventurarse en la plazuela San Agustín de Lima, sin persignarse previamente, temerosas de encuentro con las almas del purgatorio. Y una vez más, en estas cortas líneas, estamos ante una actitud antropológica, el terreno religioso cristiano en el que se mezclan los decires de la Biblia, considerada un texto sagrado, con las creencias populares que tienen que ver con apariciones de almas del purgatorio que vuelven a recorrer los espacios que en la vida conocieron. Como se puede advertir cuando se lee la literatura medieval española, los escritores de esa época, de un profundo realismo en sus descripciones, incluían los elementos fantásticos como parte de ese realismo, no como un elemento ajeno o foráneo. Gonzalo de Berceo (1852), un autor característico del siglo XIII, en sus Milagros de Nuestra Señora cuenta la historia de un guerrero que se distrae en una iglesia rezándole a la virgen y llega tarde a la batalla para la que había sido convocado, pero es felicitado por su buen comportamiento en la sangrienta refriega. Los lectores de la época acogían con naturalidad la explicación de Berceo, quien 
nos cuenta que la virgen había tomado la forma del guerrero y había participado en la batalla. En otro milagro del libro, en la historia de la abadesa que salió en cinta se cuenta la historia de una religiosa que salió en cinta y era mirada con curiosidad por sus congéneres, mientras el vientre se le iba abultando. Desesperada, la abadesa ruega a la virgen que la salve, y la madre de Jesús manda a unos ángeles que se llevan a la monja a un bosque donde da a luz a un niño que es criado por unos pastores. Regresada de forma milagrosa al convento, la monja confiesa todo a un enviado del obispo, quien decide si la virgen ha intervenido en ese parto insólito, la justicia eclesial debería abstenerse. Y así la vida continuó en el convento como si nada hubiera pasado (1852, c. XXI, párr. 500-582).

La creencia en las ánimas del purgatorio, muy difundida en la iglesia y entre los fieles, no es algo que figure en los textos originales del cristianismo, pero es algo creído por la gente a lo largo de los siglos. Y si vamos más lejos, lo que está impregnado en los fieles, es la descripción de los espacios que los seres humanos conocen después de la muerte, es la que aparece en la Comedia de Dante, infierno, purgatorio y paraíso. En la visión de Dante, lo que prevalece como lugar de los pecadores es el infierno, con sus círculos que van descendiendo hasta ubicar en el último círculo a los traidores, pero el purgatorio es una antesala al paraíso, no es un lugar de absoluto sufrimiento. Sin embargo, en la creencia popular cristiana, vigente en el siglo XIX, las almas del purgatorio, vueltas a la tierra, provocan temor entre los vivos. El persignarse, como lo dice Palma, es una especie de talismán, de conjuro, de oración a la divinidad, para evitar un encuentro del que nada bueno puede venir. En este caso, la actitud del narrador no es juzgar, sino tener una observación participativa. En la última parte de este introito Palma recurre a otra modalidad de la antropología, los decires populares, dice que lo que va a escribir, la tradición, es tal como se la contó una vieja muy entendida en historias de duendes y almas en pena. Y 
en esta frase, las creencias cristianas, arraigadas en la población en el momento de la escritura de esta tradición, coinciden con las certidumbres populares de otras percepciones de la espiritualidad, como la creencia en mundo paralelo habitado por duendes que hasta ahora mismo forma parte del imaginario de mucha gente que no asocia necesariamente esa existencia de los duendes, con la concepción cristiana. Dicho todo esto pasemos a contar el meollo de la tradición, tal y conforme la pergeñó Ricardo Palma. La tradición queda contada como si hubiera ocurrido en 1697, cuando era alcalde del crimen en Lima don Alfonso Arias de Segura, hijo de los reinos de España y hombre que, en el decir de Palma, había conquistado en el ejercicio de su cargo la reputación de severo hasta rayar en la crueldad. Reo que caía bajo su férula, solía terminar en la horca. Habitaba su señoría en la casa fronteriza a la iglesia de San Agustín y una noche oyó voces que clamaban socorro. Junto con dos alguaciles, salió a la calle y encontró a un joven de aristocrática familia agonizando. Junto al moribundo había un pobre diablo que vestía el hábito de lego agustino, con un puñal ensangrentado en la mano. Se trataba del hermano «Cominito», muy querido en la ciudad. Alborotados los frailes, encariñados con «Cominito» dieron mil argumentos para lograr su libertad, pero todas las apariencias condenaban al preso quien recibió la sentencia de ser ahorcado. El día de la vindicta pública, el propio ejecutor animó al detenido a correr y escaparse; lo hizo, con tan mala fortuna que se topó con el propio alcalde del crimen y así pasó, como dice Palma «a la tierra de los calvos» (2001, pp. 217-219). En este momento de la narración, Palma intercala unos versos, de los muchos que salían de su magín y que solía atribuir a otras personas:

La vida es comparable a una ensalada, en que todo se encuentra sin medida: que unas veces resulta desabrida y otras, hasta el fastidio, avinagrada. (p. 219) 
Este recurso, proverbial en Palma, que tiene un origen oral y popular en todas las narraciones lo usa con particular habilidad, en este caso para concluir con frases llenas de humor, una situación de por sí trágica. Con una habilidad propia de los escritores de fuste, en el segundo apartado de la tradición se cuenta de una carta que había recibido el alcalde del crimen el día anterior y que había dejado de abrir pensando que era otra de los frailes tratando de salvar la vida de su protegido. Pero la carta era de un Conde que había sido agraviado por el aristócrata asesinado y lo había mandado matar. Quedaba claro que el lego agustino era inocente de la acusación. Sabía el alcalde, recién, que su orgullo lo había cegado y había errado en el fallo. A la medianoche, salió una procesión de ánimas, con cirios encendidos que provocó terror en la autoridad. Pocos días más tarde Alfonso Arias de Segura hizo dimisión de la vara y tomó el hábito de novicio en la Compañía de Jesús, donde es fama que murió devotamente. Dos viejas, dice Palma, declararon con juramento, que desde la calle San Sebastián habían visto las luces de los cirios y ante tan autorizado testimonio no quedó en Lima prójimo que no creyera a puño cerrado en la procesión de ánimas de San Agustín (pp. 220-221). Una vez más en la entretenida red ficcional de Palma, aunque está narrada en tercera persona, puede advertirse la presencia soterrada de un narrador colectivo, perteneciente a la primera persona del plural. Nosotros, los limeños, parece decirnos Palma, creemos en el purgatorio, y creemos que las ánimas que lo habitan, de cuando en cuando regresan al valle de lágrimas para poner cierto orden en el órdago de los hechos humanos.

En una de sus tradiciones más conocidas «La gatita de MariRamos que halaga con la cola y araña con las manos», (ibíd., p. 267) Palma echa mano a otro de sus recursos favoritos, recurrir a la documentación hallada en los archivos y usarla a discreción, 
y escribe entonces como si estuviese conversando, manteniendo sí un hilo central, que es la historia que contaremos. La historia tiene la gracia de la oralidad y el desorden de la oralidad, ese desorden, como la cámara juguetona de un film, nos va dando el aire de época y el modo de pensar del virrey de aquel momento, en 1776, de Teodoro de Croix, virrey del Perú. En aquel momento, Benedicta Salazar era una limeña pizpireta de veinte abriles muy galanos, de ojos más negros que una noche de trapisonda y velados por rizadas pestañas, boca incitante como un azucarillo amerengado, cuerpo airoso y pie hermoso que invitaba a besarlo. Huérfana, vivía con una tía más gruñona que mastín piltrafero, que tenía el capricho de casarla con un compadre suyo catalán, de barba crecida. Ese catalán murmuraba, en el decir de Palma:

niña de muchos novios
que con ninguno te casas;
si te guardas para un rey,
cuatro tiene la baraja. (p. 268)

Benedicta se sentía atraída por un petimetre, Aquilino de Leuro, y un día sucedió lo que tenía que suceder, la gatita de Mari-Ramos se escapó por el tejado en amor y compañía de un gato pizpireto que olía al almizcle y tenía la mano suave. Según Palma, dice el refrán que la mula y la paciencia se fatigan si hay apuro, y lo mismo acontece con el amor. Benedicta y Aquilino se dieron tanta prisa, que medio año después de la escapatoria, hastiado el galán, se despidió a la francesa, y fue a dar con su humanidad en el Cerro de Pasco, mina boyante a la sazón. La expresión «despedirse a la francesa» figura en los diccionarios castellanos, como el acto de un miembro de la pareja de romper un compromiso, desapareciendo, sin decir adiós. La expresión es intrigante pues resulta agraviante para el pueblo francés. A su vez, los franceses no son mejores que los españoles y en la situación de separación sin despedirse usan la 
expresión «despedirse a la inglesa». En vano esperó Benedicta la vuelta del ingrato y finalmente se fue a vivir en un entresuelo de la Alameda, encerrada, y evitando entrar en relaciones con la vecindad y trabajaba como costurera de la marquesa de Soto Florido, saliendo solo los jueves por la noche para recibir o entregar vestidos. Pero un vecino advirtió su belleza, por muy escondida que estuviera. Fortunato, de quien se decía que era hijo natural del Conde de Pozosdulces, era amanuense en la alcaldía mayor de gobierno y le lanzaba chicoleos a la vecina. Benedicta jamás paró mientes a los arrumacos del vecino, pero una noche, al regresar de entregar unos vestidos, halló a Fortunato bajo el dintel de la casa, y antes de que este le endilgase uno de sus habituales piropos, ella, con voz dulce y argentina, como una lluvia de perlas le dijo «Buenas noches, vecino» y Fortunato pensó: «Al fin ha arriado bandera esta prójima y quiere parlamentar». La acompañó a su casa y ella lo invitó a pasar.

\section{Las palabras amorosas \\ son como las cuentas de un collar, \\ en saliendo las primeras \\ salen todas las demás. (p. 270)}

Ella con palabritas cortadas y melindres le dio a entender que su corazón no era de cal y ladrillo, pero como los hombres son tan pícaros y reveseros, había que dar largas y cobrar confianza antes de aventurarse en un juego en el que casi siempre todos los naipes se vuelven malillas. Llama la atención el uso de la palabra «revesero» que es un americanismo que en el Perú está confinado en el norte del país y se usa para referirse al mentiroso, al chismoso. Él juró, dice Palma, por un calvario de cruces, no solo amarla eternamente, sino las demás paparruchas que es práctica jurar en casos tales. Y para festejar la aventura añadió que en su cuarto tenía dos botellas de riquísimo moscatel que había venido de regalo para su excelencia el virrey. Y rápido 
como un cohete descendió y volvió a subir. Fortunato no daba la victoria por un ochavo menos. Apurada ya la segunda copa, buscando en ella bríos para un ataque decisivo, cuando en el reloj del puente empezaron a sonar las campanadas de las diez, y Benedicta, con gran afectación y congoja exclamó: «Estamos perdidos, entre usted en el otro cuarto y suceda lo que sucediera, ni una palabra, ni intente salir hasta que yo lo busque». A Fortunato se le volvió la carne de gallina y con la docilidad de un niño se dejó encerrar en la habitación contigua. Unas horas antes, cuenta Palma, Benedicta se había encontrado con Aquilino en la esquina de Palacio y lejos de reprocharle su conducta le habló con cariño y el amante solicitó una cita para las diez de la noche. Entre los reconciliados amantes no hubo quejas ni recriminaciones sino frases de amor. Ni una palabra del pasado. Benedicta fingió creerle y echó un narcótico en la copa de moscatel que bebía el seductor. Luego la joven lo ató fuertemente al lecho, sacó un puñal y esperó impasible que empezara a desvanecerse el poder del narcótico. Enrostró a Aquilino la villanía de su conducta, rechazó sus descargos y con mano segura hundió el acero en el corazón del hombre al que había amado tanto. Luego Benedicta le dijo al tembloroso Fortunato que había escuchado y visto todo por el agujero de la puerta: «Si aspiras a mi amor, empieza por ser mi cómplice». Y para vencer toda vacilación en el ánimo del acobardado mancebo, aquella mujer, alma de demonio encarnada en la figura de un ángel, dio un salto como la pantera que se lanza sobre una presa y estampó un beso de fuego en los labios de Fortunato. Ese beso, cuenta Palma, llevó a la sangre y a la conciencia del joven el contagio del crimen. La oscuridad de la noche era espantosa. No parecía sino que la naturaleza tomaba su parte de complicidad en el horrible delito. Entreabrióse el postigo de la casa, y por él salió Fortunato, llevando al hombro, cosido en una manta, el cadáver de Aquilino. Benedicta le seguía, y mientras con una mano le ayudaba a mantener el peso, armada con una 
aguja de hilo grueso, cosía la manta a la casaca del joven. La zozobra de este y las tinieblas servían de auxiliares a un nuevo delito. Las dos sombras vivientes llegaron al pie del parapeto del río. Fortunato, con su fúnebre carga sobre los hombros, subió el tramo de adobes y se inclinó para arrojar el cadáver. El muerto arrastró en su caída al vivo. Tres días más tarde unos pescadores encontraron en las playas de Bocanegra el cuerpo del infortunado Fortunato. Su padre, el conde de Pozosdulces, y su jefe, el marqués de Salinas, recelando que el joven hubiera sido víctima de algún enemigo hicieron aprehender a un individuo sobre el que recaían sospechas de mala voluntad con el difunto. La causa iba con pies de plomo, pero la Providencia, que vela por los inocentes, tiene recursos misteriosos para hacer la luz sobre el crimen. Benedicta, moribunda y devorada por el remordimiento, reveló todo a un sacerdote, rogándole que para salvar al encarcelado hiciese pública su confesión (ibíd., p. 267-278)

Dicho todo podemos profundizar más en la tradición. En pocos trazos, Palma nos describe la situación inicial de Benedicta Salazar, veinteañera, huérfana, en situación de merecer. Despojada de los afectos naturales, está bajo la custodia de una tía que decide por ella que debe casarse con una persona que no ama. Eso ocurría también a veces con los propios padres que designaban al candidato a yerno que les parecía. La diferencia es que los padres prodigan afecto cada día y eso es lo que no se advierte en el relato de Palma de parte de la tía, hecha para mandar. De manera que la presencia de un petimetre, Aquilino de Leuro, es razón suficiente para que Benedicta perdiera la cabeza. La atracción entre los jóvenes, ya se sabe, va más allá de las voluntades, pues es la naturaleza la que habla, la necesidad que tiene la especie de reproducirse. El niño, fruto natural de la coyunda, en las parejas de jóvenes es una sombra temida, o en ocasiones, un resultado deseado. En el siglo XVIII, sin embargo, ya empezaba a ocurrir lo que sería moneda corriente en el siglo 
XIX y más, mucho más, en el siglo XX y es la separación entre el disfrute sensual y el deseo de tener descendencia. En ese sentido, las frases que vierte Palma son muy claras: «los amantes apuran la luna de miel para dar paso a la hiel» (ibíd., p. 269). La satisfacción sexual intensa agota a los protagonistas y Aquilino se marcha sin despedirse. Como eximio narrador que es, Palma no se detiene en mostrar el dolor de la enamorada abandonada, sino que como escritor realista va describiendo lo que hacen los personajes, sin decir una palabra de lo que sienten. De esta manera el drama se va gestando como un mecanismo de relojería y Benedicta se asienta en un entrepiso y tiene una vida hasta cierto punto recoleta. Aunque escondida, la belleza de mujer llama a los varones y Fortunato, su vecino, no cesa de cortejarla. Y aquí viene algo que está en la entrelínea de toda la narración y que merece comentarse: el mundo de los sentimientos está alejado de la razón, y sin embargo es el que guía nuestros actos más importantes. Es bajo el imperio de sentimientos momentáneos que tomamos decisiones definitivas. Habiéndose encontrado Benedicta, con su antiguo amante Aquilino, pacta una cita con él para las diez de la noche. Antes, como gatita de Mari-Ramos, mueve la cola a Fortunato, lo invita a su casa y lo esconde en el cuarto vecino cuando llega Aquilino y el drama se precipita. Un torrente de sentimientos de venganza la lleva a cometer un doble crimen que resulta espeluznante para el más curtido lector. Palma, escritor nacido en 1833, no podía conocer, al parecer, las narraciones de Poe, muerto en 1849, plenas de horror, de tal manera que no puede hablarse de influencia de uno sobre el otro. Pero ese mismo escalofrío que sentimos cuando leemos a Poe, lo experimentamos cuando advertimos que Benedicta, en esa noche lóbrega en la que Fortunato lleva en hombros el cadáver de Aquilino, va cosiendo con una fuerte aguja y un ancho hilo, la casaca del vecino con el costal que lleva como un fardo el cuerpo del asesinado. George Simenon, el gran narrador de novelas policiales del siglo XX, 
solía decir que él empezaba narrando cualquier cosa, en medio ponía un crimen, y después resolvía. Eso es precisamente lo que hace Palma, por partida doble y resuelve en una especie de anticlímax, que da un respiro final al atribulado lector que ha ido de suspenso en suspenso durante toda la narración. Quedan para siempre en nuestra memoria, esos dos hombres precipitándose al río, uno muerto y el otro vivo, arrastrándose uno al otro a la región de las sombras.

Veamos ahora una tercera tradición de Palma. Se trata de una divertida historia titulada «Una aventura amorosa del padre Chuecas» (2003, p. 108) y narra la historia del sacerdote fray Mateo Chuecas y Espinosa que nació en Lima en setiembre de 1788 y vistió el hábito de novicio en 1802. Conocía el latín y a los poetas clásicos; cansado de la vida austera, se lanzó a la de los escándalos. Del padre Chuecas podría decirse lo que Lope de Aguirre escribió, refiriéndose a los frailes del Perú: «La vida de los frailes es tan áspera, que cada uno tiene, por cilicio y penitencia, media docena de mozas» (ibíd., p.109). Jugador, impertérrito y libertino como un Tenorio, encontrábase rara vez en su convento y con frecuencia en los garitos y lupanares. Manejaba el puñal, dice Palma, con la destreza y agilidad de un maestro de armas y cuando en una jarana se armaba pendencia y él estaba en copas, no escapaban de su puñalada recia y corte limpio ni las cuerdas de la guitarra. Palma afirma haberlo conocido en 1890, cuando Chuecas frisaba más de sesenta años. Así que el meollo de la tradición se origina en conocimientos orales que el escritor tiene y que administra con la particular habilidad que tenía. El padre Chueca sabía improvisar sencillos y elocuentes cantares en las fiestas a las que concurría:

El verme así no te asombre, porque es mi amor tan sin par que aquí me he puesto a pensar si hay más que hacer por el hombre. (ibíd., pp. 108-114). 
Dice Palma que la época del padre Chuecas vivía en Malambo una mocita de medio pelo en edad de merecer que se llamaba Nieves Frías. Su paternidad, el franciscano bailaba el agua de nieve por apoderarse del corazón de la muchacha y en vía de cantar victoria estaba cuando se le atravesó un galán argentino. Estando en una fiesta, la madre de la doncella, que favorecía al enamorado del sur, le pidió al padre Chuecas que improvisará unos versos con el pie «Córdoba del Tucumán». Y el fraile recitó:

Brindo, preciosa doncella

porque en tus pómulos rojos

jamás contemplen mis ojos

de las lágrimas la huella.

Brindo, en fin, porque tu estrella

que atrae como el imán

a tanto y tanto galán

que se embelesa en tu cara,

nunca brille alegre para

Córdoba de Tucumán. (ibíd. pp. 115-116)

Un aplauso estruendoso selló la recitación y el satirizado pretendiente tuvo que felicitar al sacerdote improvisador. Más tarde el argentino respondió con una redondilla, con menos gracejo, pero bastante explícita:

Brindo por el bien que adoro,

y para que sepan todos

que el amor se hizo para los hombres

y para los frailes se hizo el coro. (pp. 116-117)

El fraile no quedó conforme y recitó:

Cordobés infelice que al Parnaso,

por numen chabacano conducido,

pretendes ascender, idetente huaso!

no profanes sus cumbres atrevido. 
Advierte que la lira no es el lazo;

pues quizá temerario has presumido

que son las Musas, a las que haces guerra,

las mulas que amansabas en tu tierra. (ibíd., p. 117)

Una carcajada general y un iviva el padre! contestaron a la valiente octava. El argentino perdió los estribos y se fue sobre el fraile, quien esperaba la embestida, daga en mano. Armose la marimorena: chillaron las mujeres y arremolináronse los hombres. Por fortuna acudió la policía a tiempo para impedir que los adversarios se abriesen ojales en el pellejo y los condujo a chirona. El padre Chuecas pasó seis meses de destierro en Huaraz. A su regreso supo que la paloma había emprendido el vuelo a Córdoba de Tucumán. Esta tradición hace reposar su encanto sobre el insólito título, que nos envía a la imagen de un sacerdote pecador. Ese ingrediente ya la hace atractiva. Luego se dicen generalidades punzantes sobre la vida licenciosa del clérigo, para poner un ejemplo galano, la disputa por Nieves Frías. Y aquí es donde la pluma de Palma se luce más. Ignoramos si los versos que aparecen en el texto son efectivamente del padre Chuecas o son producto del magín del propio Palma. En uno o en otro caso, muestran ese gracejo zumbón, esa gracia sin igual que nutre a todas las Tradiciones, la habilidad suprema del escritor que mantiene en vilo al ánimo del lector (ibíd., pp. 117-1 18)

Hemos visto tres tradiciones de distinta índole, que retratan a la Lima virreinal desde distintos ángulos y perspectivas, el mundo de las creencias colectivas, con aquella que habla de la procesión de las ánimas, el mundo de las pasiones que llevan al crimen, con «la gatita de Mari-Ramos que halaga con la cola y araña con las manos», el círculo de la diversión pecaminosa del sacerdote Chuecas, sabio en latines y conocedor del arte de manejar puñales. Palma, resumiendo, tiene una receta general: mezcla lo sólito con lo insólito y maneja el lenguaje con la precisión con que lo harían los dioses si fuesen humanos. 


\section{Referencias bibliográficas}

Berceo, G. de (1852). Milagros de Nuestra Señora. Edición digital a partir de la de Florencio Janer, en Biblioteca de Autores Españoles, vol. 57, pp. 103-131 (Madrid, Real Academia, 1852), cotejada con las ediciones críticas de Antonio García Solalinde (Madrid, Espasa Calpe, 1964, reimpresión), Daniel Devoto (Valencia, Castalia, 1967) y Michael Gerli (Madrid, Cátedra, 1997). Asumimos la numeración de las cuadernas propuesta por Gerli. Recuperado de http://www. cervantesvirtual.com/obra-visor/milagros-de-nuestra-senora--1/html/ fedb56be-82bl-1 ldf-acc7-002185ce6064_2.html\#I_0_

Flores, A. (1984). Aristocracia y plebe. Lima, 1760-1830. Lima: Mosca Azul.

Palma, R. (1956). Tradiciones peruanas completas. Edición y prólogo de Edith Palma. Madrid: Aguilar.

. (2001). Tradiciones peruanas. Selección y prólogo de Carlos Garayar. Lima: Empresa Editora El Comercio S.A

. (2003). Tradiciones peruanas. Argentina: Biblioteca Virtual Universal. Recuperado de https://www.biblioteca.org.ar/libros/92804.pdf

Ribeyro, J. R. (1981). «Gracias, viejo socarrón». En Debate. N. 11. Lima, p.11.

Salazar, S. (1964). Lima, la horrible. México: Biblioteca Era.

Recibido el 10 de septiembre de 2020 Aprobado el 10 de octubre de 2020 